九州大学学術情報リポジトリ

Kyushu University Institutional Repository

Numerical simulation of fatigue crack

propagation under superimposed stress histories containing different frequency components with several mean stress conditions

Matsuda, Kazuki

Department of Civil and Structural Engineering, Kyushu University

Gotoh, Koj i

Department of Marine Systems Engineering, Kyushu University

http://hdl. handle. net/2324/4751318

出版情報: Marine structures. 41，pp.77-95，2015-04. International Ship and 0ffshore Structures Congress

バージョン :

権利関係 : 
Title: Numerical simulation of fatigue crack propagation under superimposed stress histories containing different frequency components with several mean stress conditions

Kazuki MATSUDA

Department of Civil and Structural Engineering, Kyushu University, Japan

\section{Koji GOTOH*}

Department of Marine Systems Engineering, Kyushu University, Japan

* Corresponding author

744 Motooka, Nishi-ku, Fukuoka, 819-0395, Japan

Email: gotoh@nams.kyushu-u.ac.jp

Phone: +81-92-802-3457

Fax: $+81-92-802-3368$ 


\section{Abstract}

Fatigue crack propagation behavior under superimposed stress histories containing different frequency components with several mean stress conditions was investigated. Numerical simulation of fatigue crack propagation based on an advanced fracture mechanics approach using the RPG (Re-tensile Plastic zone Generating) stress criterion for fatigue crack propagation was improved to extract the effective part from the applied stress history for fatigue crack propagation. The parameter, which is based on the plastic hysteresis energy consumed in the vicinity of a crack tip, was applied and implemented into the numerical simulation code of fatigue crack propagation. Fatigue crack propagation tests under various superimposed stress conditions with several mean stress conditions were performed and compared with the fatigue crack propagation histories obtained from the improved numerical simulations. These comparisons show the validity of the proposed procedure for extracting the effective stress history from the superimposed stress histories with different frequency components and mean stresses. Additionally, practical fatigue strength evaluations based on the linear cumulative fatigue damage parameter were conducted to investigate the tendency of the fatigue damage value under these stress conditions. 


\section{Introduction}

Ship hull structures are subjected the additional stresses due to ship's vibrations as well as the wave bending stresses as during a voyage. Such vibrations are categorized into two types; transient vibrations caused by wave impact or slamming, referred to as whipping, and resonance vibrations caused by oscillating loading along the hull, referred to as springing. The magnitude and effect of these vibrations depends on the ship's design, operating conditions such as voyage speeds and heading angle with respect to wave direction, and the sea states encountered. In general, hull structures are subjected to the superimposed stresses of the wave bending and vibration components.

The significance of such whipping and springing on the fatigue strength of hull structures has become more notable in recent years, with the rise in ship size which lowers the natural frequencies of the hull. Fricke and Paetzold [1] presented recent studies related to these problems. Toyoda et al. [2] investigated the fatigue damage caused by ordinary wave fluctuation and the elastic response caused by whipping and found that whipping increased the fatigue damage by 3.9 times.

Generally, fatigue strength evaluations under variable loading histories including superimposed stresses are performed using the S-N curves approach based on the rain flow stress cycle counting method [3] and the linear cumulative damage law [1][4][5]. Although these studies validated the S-N curves approach for fatigue strength evaluation under superimposed stresses, their conclusions were limited for the following reasons.

- The evaluation was based on experimental results under limited stress conditions and the interpretation of the physical meaning of the evolution of fatigue damage seems to be insufficient.

- $\quad$ The S-N curves approach cannot give the fatigue crack growth history.

- The method for identifying the critical fatigue crack length found in in-service structures from S-N curves has not yet been established [6]. 
To overcome the limitation of the S-N curves approaches, fatigue strength evaluation using the fracture mechanics approach can be applied. However, most fatigue life assessments using the fracture mechanics approach, e.g., Paris' law and Elber's law, cannot quantitatively estimate the retardation and acceleration of crack propagation because of insufficient consideration of fatigue crack opening/closing behavior caused by the crack wake. It is essential to consider the cyclic plasticity ahead of a crack tip when estimating fatigue crack growth behavior quantitatively [7].

In previous studies, the numerical simulation of fatigue crack propagation based on an advanced fracture mechanics approach using the RPG (Re-tensile Plastic zone Generating) stress criterion [7] was improved to enable the extraction of the effective stress history for fatigue crack propagation under superimposed stress histories [8][9]. The critical value of the plastic energy, which corresponds to the plastic hysteresis of the stress versus strain curve occurring in the vicinity of a crack tip, is defined as the control parameter for extracting the effective stress history of fatigue crack propagation. This control parameter is implemented in the numerical simulation code for fatigue crack propagation considering the fatigue crack opening/closing behavior using the RPG stress criterion. The validity of this method is confirmed by comparing the measured fatigue crack growth curves, which corresponds to the history of the fatigue crack length as a function of the number of applied stress cycles, with the estimated ones. These comparisons are, however, limited under one constant mean stress condition.

This study highlights fatigue crack propagation behavior under superimposed stress histories containing different frequency components with several mean stress conditions. Fatigue crack propagation tests and numerical simulations of fatigue crack propagation under several mean stress conditions were performed. Furthermore, we investigated the applicability of the practical fatigue strength evaluation procedure based on the S-N curves approach. 


\section{Fatigue crack propagation test}

We performed fatigue crack propagation tests under superimposed stress histories with several mean stress conditions.

\subsection{Specimen configuration and materials}

The specimen configuration is shown in Fig. 1. Center cracked tensile (CCT) specimens were used. Both edges of the centered notch were cut using electrical discharge machining. The test specimens, 4-mm thick with a centered notch, were made from mild steel (SM400B by JIS G 3106; [10]) 16-mm thick plate. The mechanical properties and chemical compositions are shown in Tables 1 and 2, respectively.
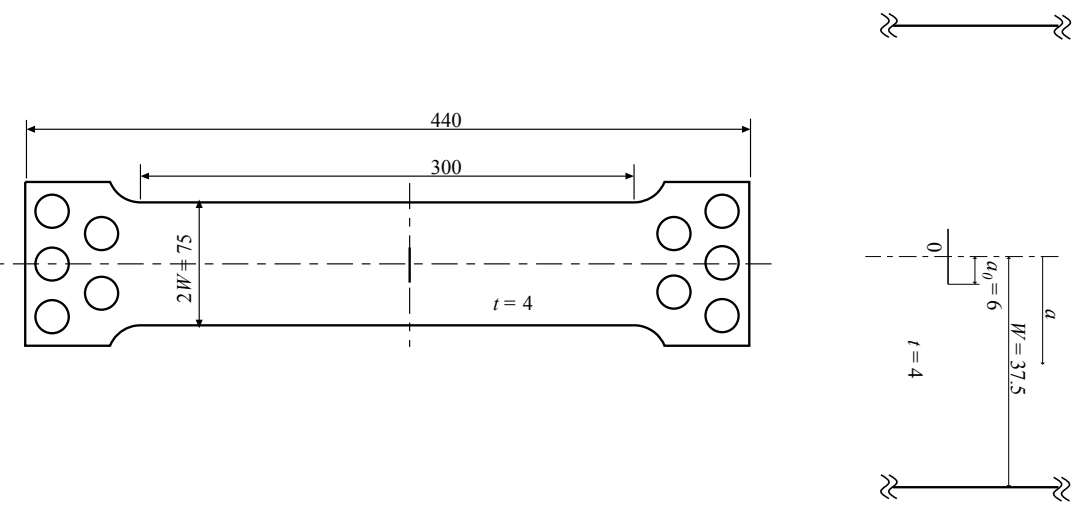

(a) General view

(b) Detail of an initial crack

Fig. 1 Specimen configuration used.

Table 1 Mechanical properties.

\begin{tabular}{ccc}
\hline Yield Strength $[\mathrm{MPa}]$ & Tensile Strength $[\mathrm{MPa}]$ & Elongation [\%] \\
\hline 299 & 452 & 33 \\
\hline
\end{tabular}


Table 2 Chemical composition (wt $\%$ ).

\begin{tabular}{ccccc}
\hline $\mathrm{C}$ & $\mathrm{Si}$ & $\mathrm{Mn}$ & $\mathrm{P}$ & $\mathrm{S}$ \\
\hline 0.15 & 0.20 & 1.05 & 0.009 & 0.002 \\
\hline
\end{tabular}

\subsection{Applied stress conditions}

The applied stress conditions performed in this study are shown in Table 3. Constant amplitude stress with a low frequency was applied in test L4t. The applied stress condition of test Sa4t_M was obtained by superimposing the constant stress amplitude with a high frequency which was five times that of the low frequency. In test Pa4t_M the applied stress condition corresponded to the envelope of the applied stress cycles of test Sa4t_M. In tests Sa4t_H and Pa4t_H the mean stress was 30 MPa higher than in tests Sa4t_M and Pa4t_M, respectively. Conversely, in tests Sa4t_L and Pa4t_L the mean stress was $30 \mathrm{MPa}$ lower than in tests Sa4t_M and Pa4t_M, respectively. Moreover, the mean stresses for tests Sa4t_LL and Sa4t_LLL were $45 \mathrm{MPa}$ and $60 \mathrm{MPa}$ lower than that of test Sa4t_M, respectively. In case of tests Pa4t_M, Pa4t_H and Pa4t_L, cyclic frequencies were increased to five times because of the experimental time saving.

Subsequently, test Va4t_HL was performed under a variable mean stress condition obtained by repeating the conditions of tests Sa4t_H and Sa4t_L for 20,000 cycles. Test Va4t_HML had a variable mean stress condition obtained by repeating the conditions of tests Sa4t_M, Sa4t_H, Sa4t_L, and Sa4t_M for 20,000 cycles as the block programming loading condition.

Tests Ra4tD_M and Ra4tD_HML were designed to investigate the fatigue crack growth in ship hull structures under seaway loadings with whipping. Test Ra4tD_M was performed under constant mean stress conditions and test Ra4tD_HML had variable mean stress conditions, where the mean stress varied as 65 $\rightarrow 95 \rightarrow 65 \rightarrow 35 \mathrm{MPa}$ for 20,000 cycles. 
Table 3 Applied stress conditions.

\begin{tabular}{|c|c|c|c|}
\hline \multirow{2}{*}{$\begin{array}{l}\text { Test } \\
\text { ID }\end{array}$} & \multicolumn{2}{|c|}{ Stress amplitude $[\mathrm{MPa}]$} & \multirow{2}{*}{ Mean stress $[\mathrm{MPa}]$} \\
\hline & High frequency component & Low frequency component & \\
\hline \multirow[b]{2}{*}{ 莳 } & 0 & 35 & 65 \\
\hline & (100) & 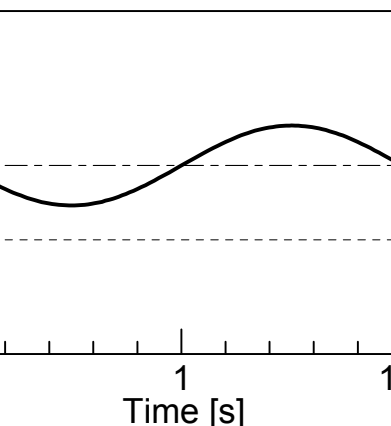 & 2 \\
\hline \multirow[b]{2}{*}{ 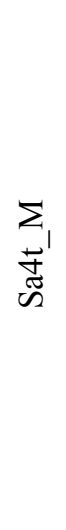 } & 35 & 35 & 65 \\
\hline & क & 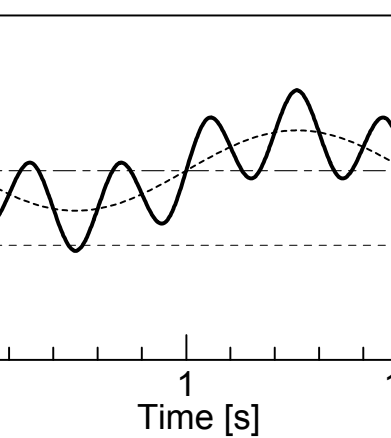 & 2 \\
\hline \multirow[b]{2}{*}{ 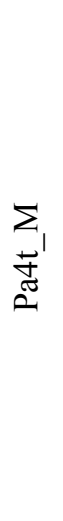 } & 0 & 70 & 65 \\
\hline & (100 & $\frac{1}{0.2}$ & 0.4 \\
\hline
\end{tabular}




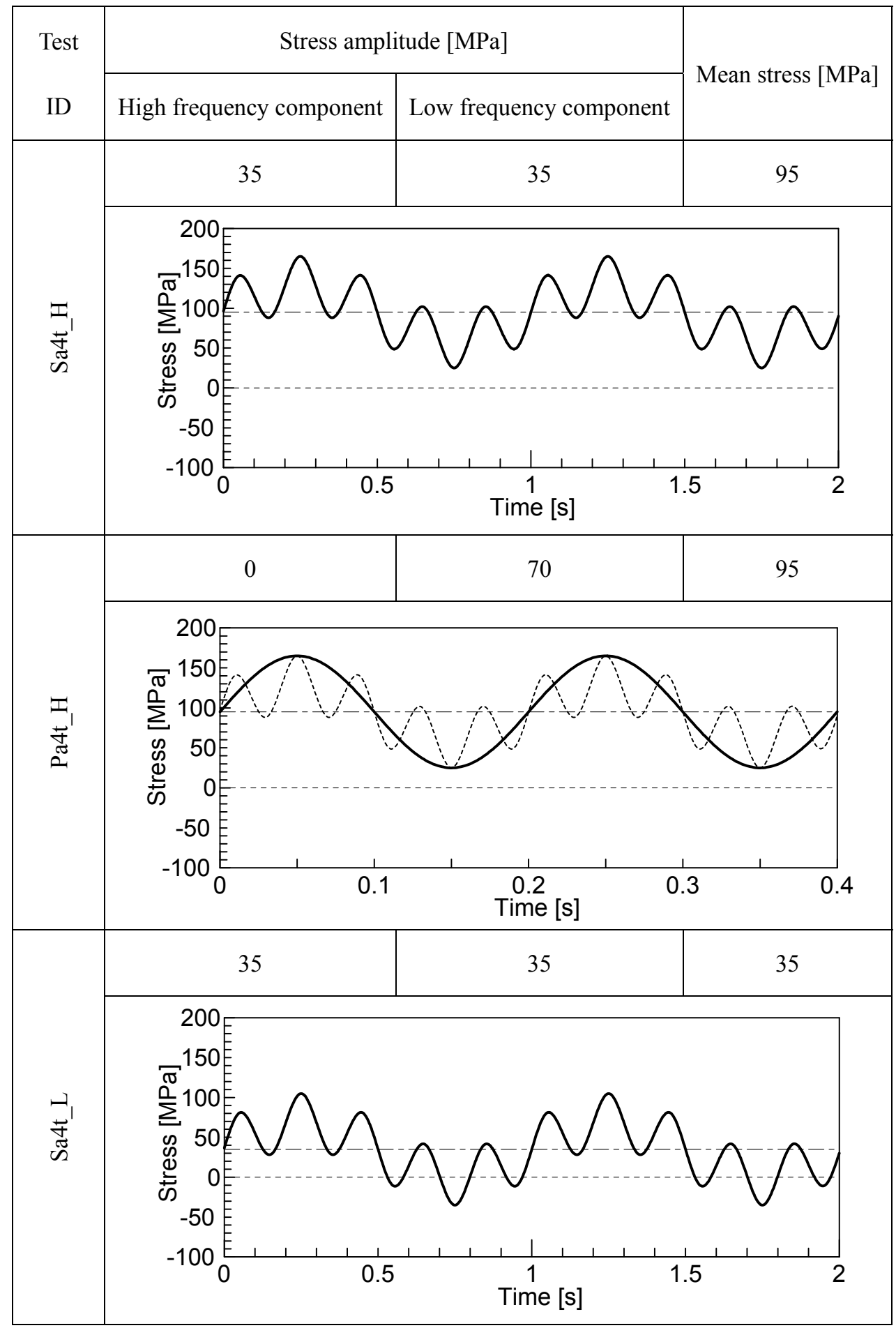




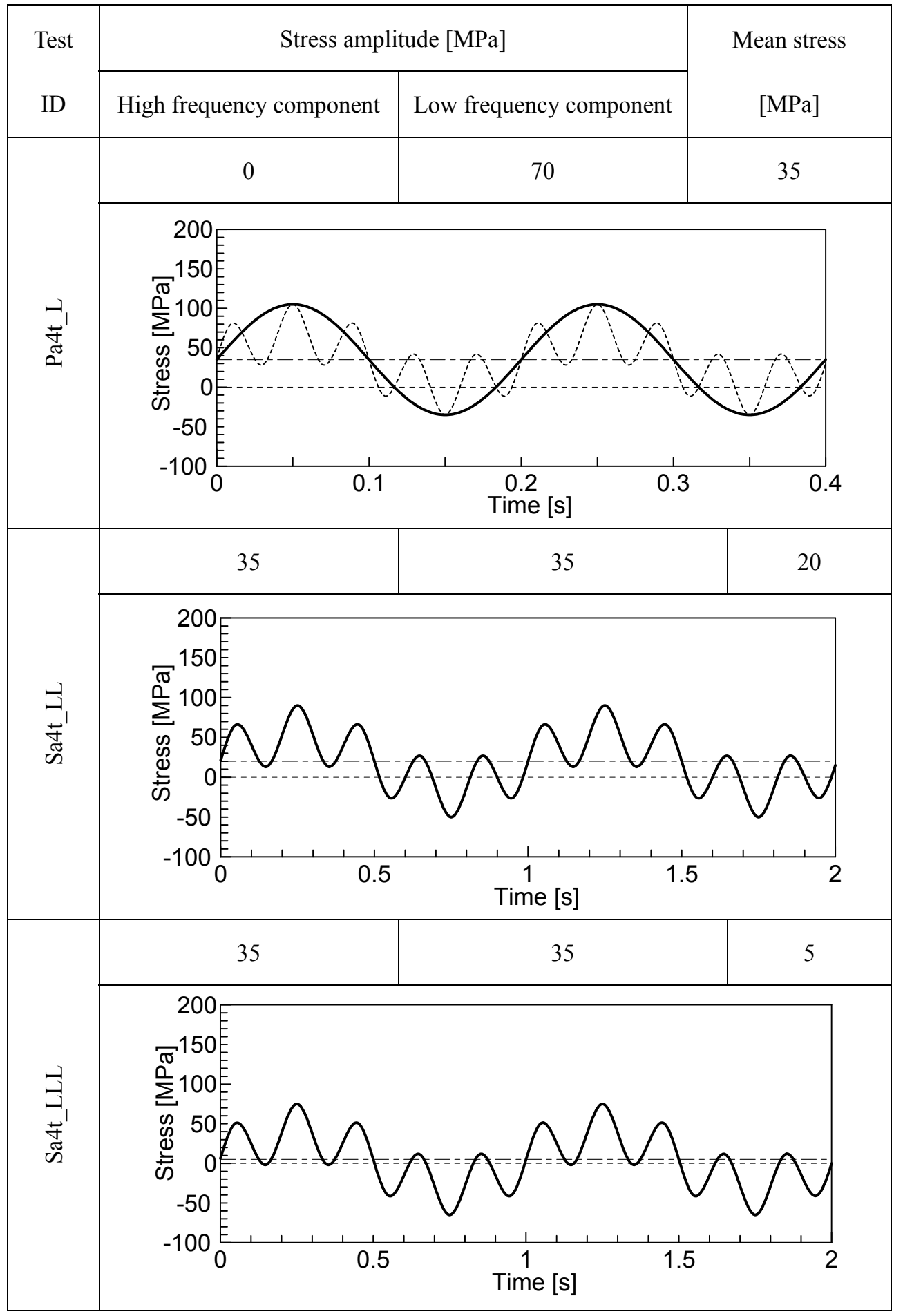




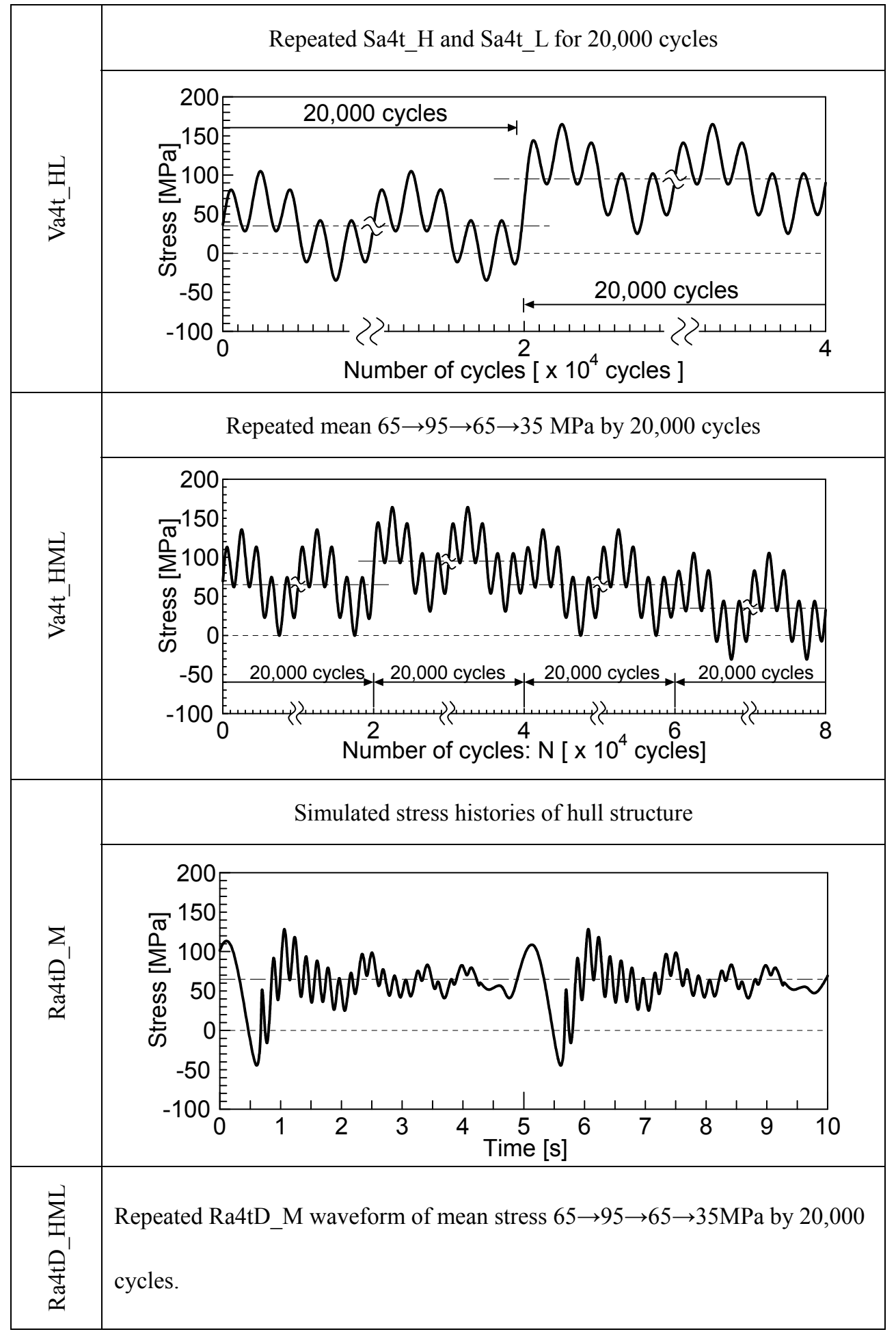




\subsection{Fatigue test results}

Figure 2 shows the results of the fatigue crack propagation tests. The vertical axis shows the fatigue crack propagation length, which starts at $7 \mathrm{~mm}$ from the center of the specimen. The data from the very early and uncertain stages of the fatigue crack initiation and growth were omitted. The horizontal axis denotes the number of low cycles. The results show the following properties.

i) The crack propagation rates of the superimposed stress conditions were higher than those of each envelope stress condition in each test (the cycle ratio when a crack length reached $12 \mathrm{~mm}$ : $\mathrm{Sa} 4 \mathrm{t} \_\mathrm{H} / \mathrm{Pa} 4 \mathrm{t} \_\mathrm{H}=0.655, \mathrm{Sa} 4 \mathrm{t} \_\mathrm{M} / \mathrm{Pa} 4 \mathrm{t} \_\mathrm{M}=0.627$, and Sa4t_L/Pa4t_L $=0.752$ )

ii) The higher crack propagation rates were obtained under each mean stress condition according to the increasing mean stress values. The cycle ratios when the crack length reached $12 \mathrm{~mm}$ were: Sa4t_H/Sa4t_M: 0.977, Sa4t_L/Sa4t_M: 2.535, Sa4t_LL/Sa4t_M: 2.783, and Sa4t_LLL/Sa4t_M: 4.190.

iii) The differences of the mean stress in tests Sa4t_H, Sa4t_M, Sa4t_L, and Sa4t_LLL were all $30 \mathrm{MPa}$ but the differences in the crack propagation rates were not equal.

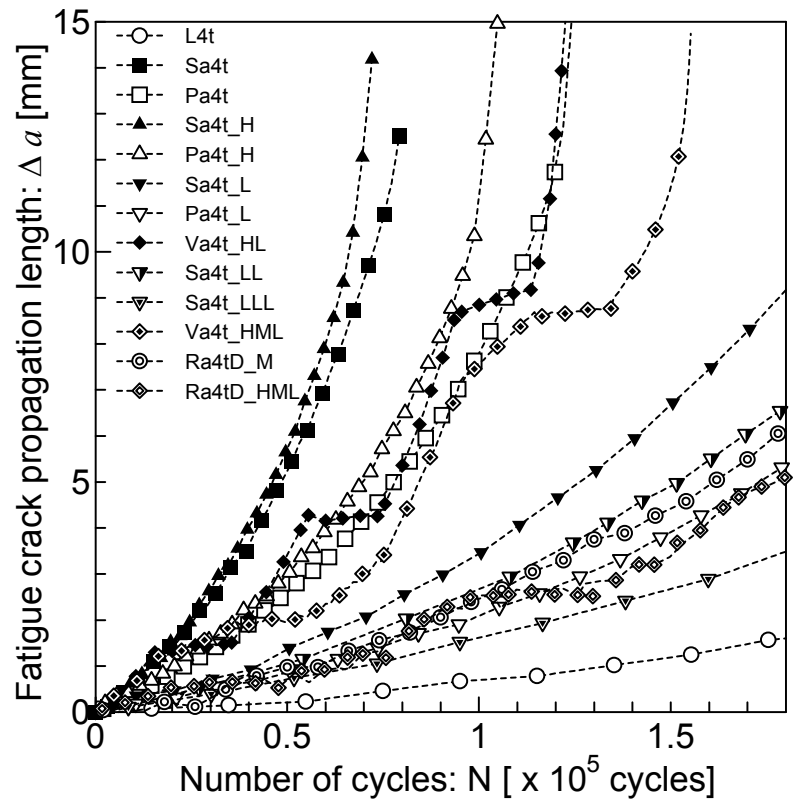

Fig. 2 Measured fatigue crack growth curves under various applied stress conditions. 
3. Numerical simulation of fatigue crack propagation

3.1 Overview of numerical simulation based on the strip yield model [7]

The numerical simulation of the fatigue crack propagation was performed by using our developed numerical simulation which models the fatigue crack opening/closing behavior and estimates the relationship between the fatigue crack length and the number of applied stress cycles. Applied numerical simulation model is based on the strip yield model with the stress intensity factor weight function.

Overview of this model is explained briefly according to reference [7].

The condition of the displacement continuity ahead of the physical crack tip is not satisfied in the primitive strip yield model. To eliminate this deficiency, the chink corresponding to the virtual crack opening displacement (COD) in the plastic zone ahead of a physical crack tip is plugged up by a small segment shown in Fig. 3.

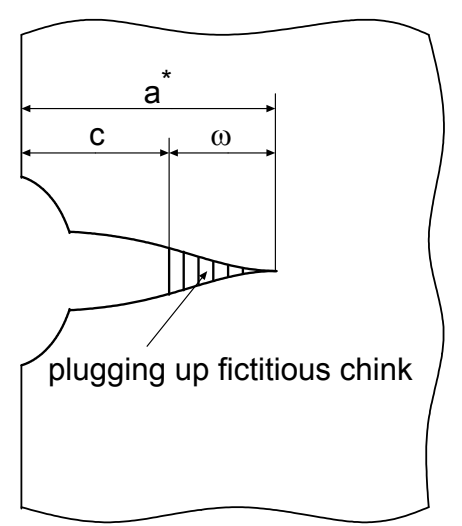

a) Crack surface displacement for fictitious crack.

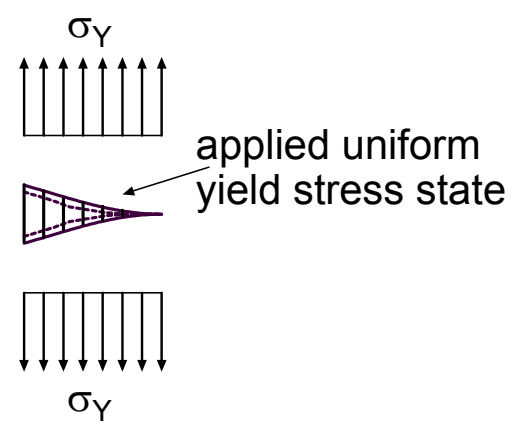

b) Segment plugged up region with fictitious COD in plastic zone.

Fig.3 Schematic illustration of the crack surface displacements for the fictitious crack from the strip yield model and the approximation of the physical COD. 
After loading the segment with uniform elastic stresses of the yield stress magnitude under an appropriate triaxial constraint condition, it deforms elastically to accurately fit the fictitious COD in the plastic zone of strip yield model, as indicated by the solid line in Fig. 3 b). Inserting the segments enables to satisfy the displacement continuity and improves the model performance compared to the original concept of the strip yield model. The advantage of this model's approach can be proved by considering Newman's crack closure model [11] [12] for which the segment material is assumed to be the rigid-plastic.

If the current tensile plastic zone extends beyond the previous plastic zone, the original strip yield model should be satisfied. A layer of the residual tensile deformations, which is commonly known as the crack wake, generated by the previous loading is on fatigue crack surfaces. The thickness of the layer $L_{j}$ is assumed to equal length of the segment after removing the applied stress, because the perfect elasticplastic material of the layer is assumed.

$$
L_{j}=V_{j} /\left(1+\lambda \sigma_{Y} / E^{\prime}\right),
$$

where

$L_{j}: \quad$ thickness of the plasticity elongated (crack wake) layer at $x_{j}$,

$V_{j}: \quad$ crack opening displacement (COD) at $x_{j}$

$x_{j}: \quad$ reference point on the $x$ axis

$\sigma_{Y}: \quad$ Material yield strength,

$\lambda$ : $\quad$ plastic constraint factor and 


$$
E^{\prime}=\left\{\begin{array}{cc}
E & {[\text { Plane stress }]} \\
E /\left(1-v^{2}\right) & {[\text { Plane strain }]}
\end{array} .\right.
$$

Strain in a fictitious crack tip can be identified from the crack opening displacement defined by Eq. (1).

If the present plastic zone is embedded in the previous plastic zone, the superposition principle shown in

Fig. 4 is satisfied based on the strip yield model and the following relations are introduced.

$$
V_{j}=P \sum_{i=1}^{n} s_{i} F\left(x_{j}, x_{i}, a^{*}\right)-\sum_{i=1}^{n} \sigma_{i} F\left(x_{j}, x_{i}, a^{*}\right)+\sum_{i=1}^{n} \sigma_{i}^{R} F\left(x_{j}, x_{i}, a^{*}\right),
$$

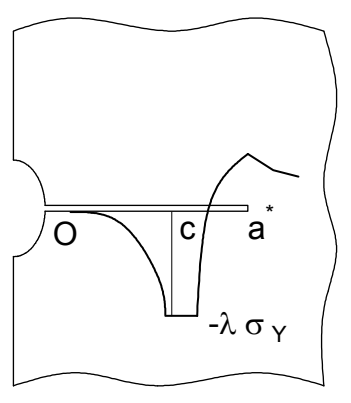

(a)

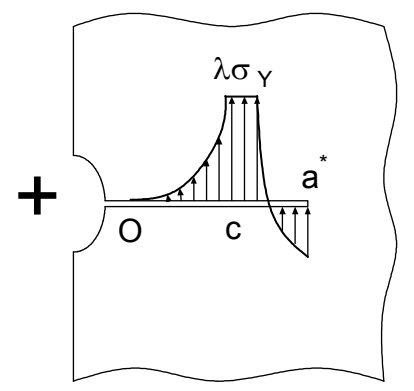

(d)

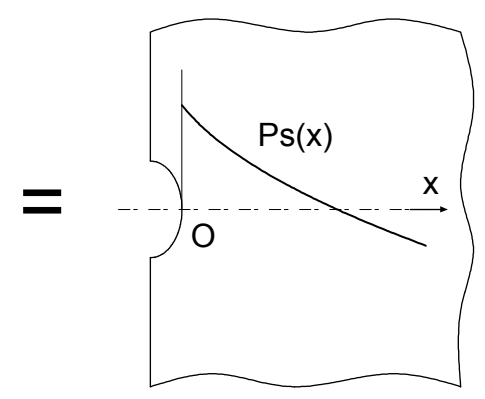

(b)

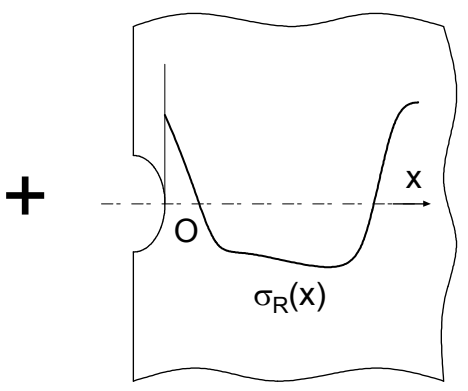

(e)

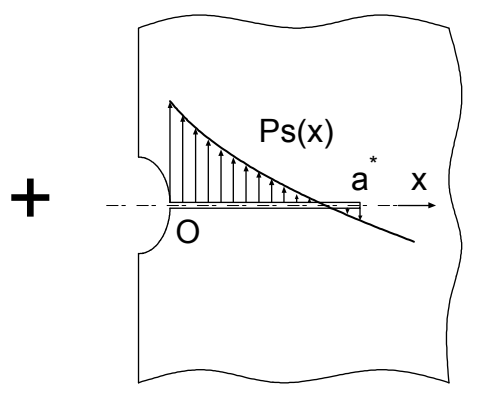

(c)

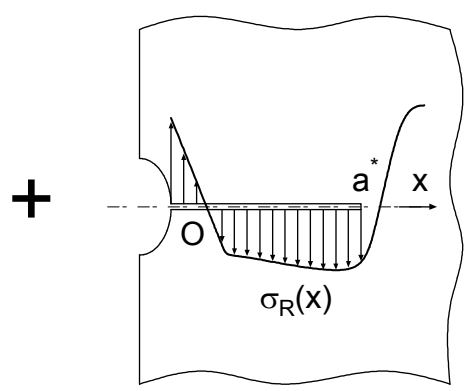

(f)

Fig.4 Application of the superposition principle to computed COD in the plastic zone embedded in the previous plastic zone. 
where

$P: \quad$ magnitude of the external load,

$s_{i}: \quad \quad$ working stress at $x_{i}$ per unit external load under no crack condition,

$F\left(x_{j}, x_{i}, a^{*}\right): \quad$ COD at $x_{j}$ when a uniform unit stress acts between $x=B_{i}$ and $B_{i+l}$ on the crack

surfaces, $x_{i}=\left(B_{i}+B_{i+1}\right) / 2$,

$a^{*}: \quad \quad$ length of the fictitious crack (tip of the tensile plastic zone),

$\sigma_{I}: \quad$ working stress at $x_{i}$ along the crack line and

$\sigma_{i}^{R}: \quad$ pre-existing residual stress at $x_{i}$.

If an element remains elastic, the following relation should be satisfied in the fictitious crack region and

the crack closure region.

$$
L_{j}=V_{j} /\left(1+\sigma_{j} / E^{\prime}\right)
$$

By substituting Eq. (2) into Eq. (3), $\sigma_{j}$ can be obtained by solving the resulting linear system of equations through an iterative method with the following constraints:

For the region ahead of the crack tip,

$$
\begin{aligned}
& \text { if } \sigma_{j}<-\lambda \sigma_{Y} \text {, then } \sigma_{j}=-\lambda \sigma_{Y} \\
& \text { and } \\
& \text { if } \sigma_{j}<\lambda \sigma_{Y} \text {, then } \sigma_{j}=\lambda \sigma_{Y}
\end{aligned}
$$


For the plastic wake zone,

$$
\begin{aligned}
& \text { if } \sigma_{j}>0 \text {, then } \sigma_{j}=0 \\
& \text { and } \\
& \text { if } \sigma_{j}<-\lambda \sigma_{Y} \text {, then } \sigma_{j}=-\lambda \sigma_{Y}
\end{aligned}
$$

From the solution of $\sigma_{j}, \mathrm{COD}$ is obtained by Eq. (2) at the minimum external load during the cyclic load $\left(P_{\min }\right)$ or the maximum one $\left(P_{\max }\right)$ if the tensile plastic zone is inside the previous tensile plastic zone. The RPG stress is obtained when the stress in the bar element adjacent to a crack tip reaches the yield stress during the loading reversal. The crack opening stress can be obtained when the stress in the bar element adjacent to a crack tip is equal to zero during the loading reversal.

3.2. The concept of extracting the effective loading history for fatigue crack propagation [8][9] To perform quantitative analysis of fatigue crack propagation under the superimposed stress history, it is necessary to extract the "effective" stress components for fatigue crack propagation from the applied stress history.

The location of the crack tip changes during the cyclic loading because of the fatigue crack opening/closing phenomenon. Figure 5 shows a schematic illustration of a single stress cycle in fatigue crack propagation $\left(S_{\max }^{(i)} \rightarrow S_{\min }^{(i)} \rightarrow S_{\max }^{(i+l)}\right.$ ). The plastic behavior near the crack tip is analyzed as follows. 


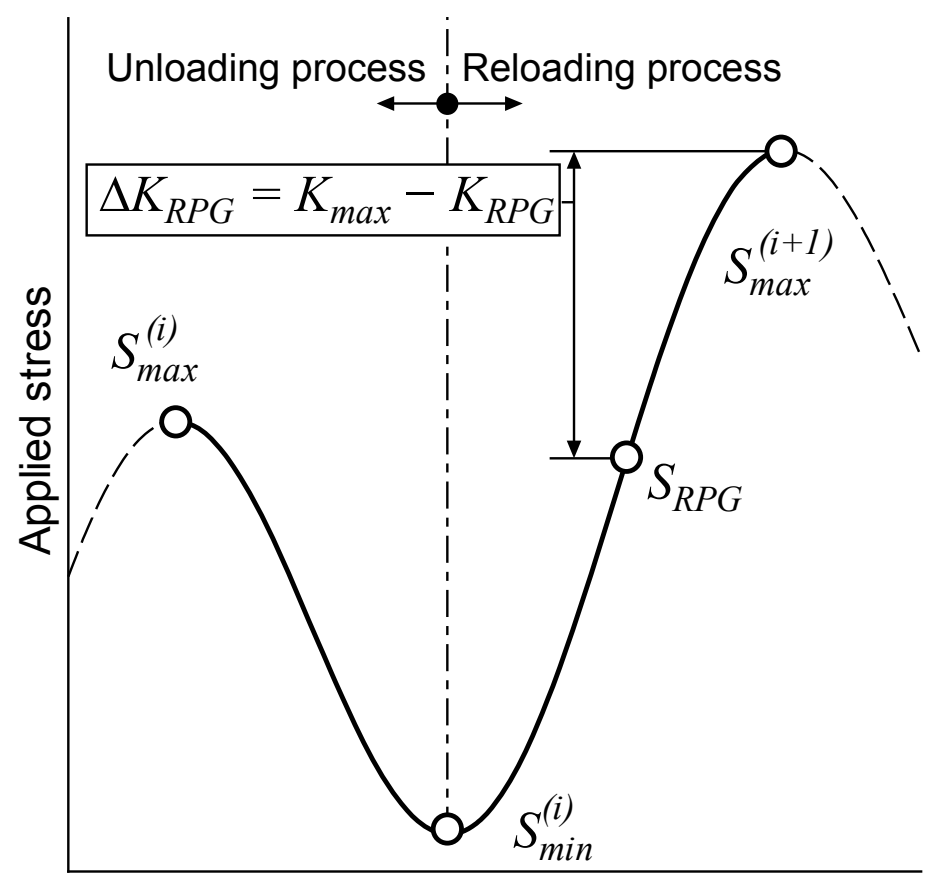

Time

Fig. 5 Schematic illustration of one cycle during the cyclic loading.

We assume that the tensile plastic zone is generated near the crack tip at the maximum stress $\left(S_{\max }^{(i)}\right)$. The crack tip starts closing and a compressive plastic zone is generated in the vicinity of the crack tip during the unloading process $\left(S_{\max }{ }^{(i)} \rightarrow S_{\min }{ }^{(i)}\right)$. In the subsequent reloading process $\left(S_{\min }{ }^{(i)} \rightarrow S_{\max }{ }^{(i+1)}\right)$, the crack tip starts opening again and the tensile plastic zone is re-generated near the crack tip. The alternating plastic zone is defined by the overlapped region of the compressive plastic zone during the unloading and the tensile plastic zone during reloading. Detailed observation of the crack opening/closing phenomenon and the generation and growth of the plastic zone throughout one loading cycle demonstrates that no plastic work occurs in the loading range from the crack tip opening stress to the RPG stress $\left(S_{R P G}\right)$.

We focus on the alternating plastic region because the plastic hysteresis energy consumed near the crack tip provides the driving force for the fatigue crack. For fatigue crack propagation, it is necessary to provide a certain amount of plastic work to provide the crack driving force during one loading cycle, and small 
loading amplitudes which cannot provide sufficient driving force for the crack should be ignored in the numerical simulation of fatigue crack propagation. The plastic work consumed in the alternating plastic zone is obtained by the following equation:

$$
\xi=\int_{\tilde{\omega}} \sigma_{Y} d \varepsilon_{p} d x,
$$

where $\sigma_{Y}$ is the yield strength of the material, $d \varepsilon_{p}$ is the plastic strain increment near the crack tip, and $\tilde{\omega}$ is the alternating plastic zone length. The effective stress history for the fatigue crack propagation is extracted from the raw data of the applied stress history if the alternating plastic work $x$ during one stress cycle calculated by Eq. (4) exceeds the appropriate threshold $\xi_{\text {limit. }}$. If the value of $\xi$ during one stress cycle is less than the threshold $\xi_{\text {limit, }}$ this stress cycle is ignored. Examples of the extracting procedure are illustrated in Fig. 6. 

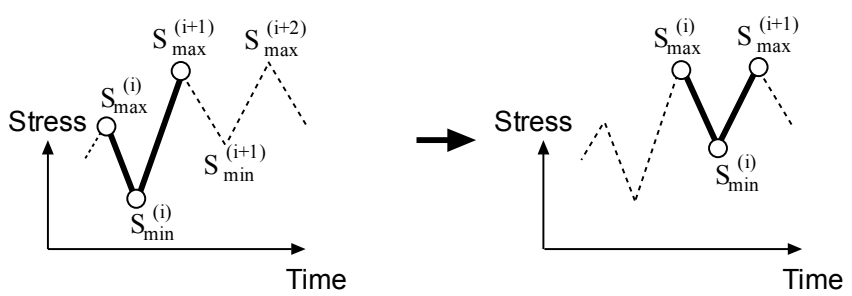

(a) Previous method

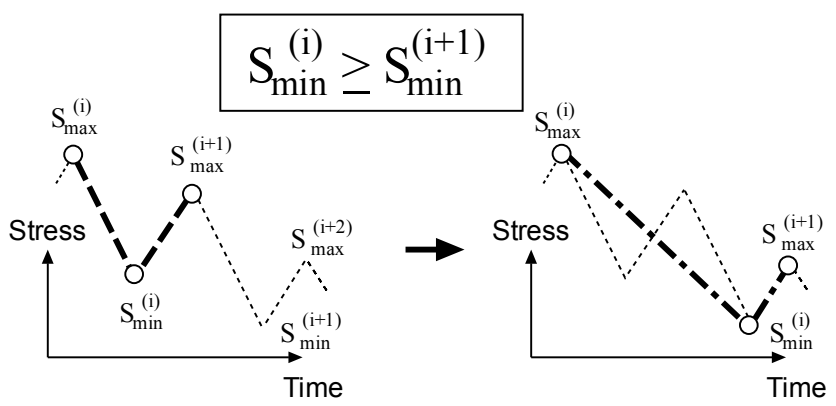

(b) Effective stress sequence extracting method Pattern 1

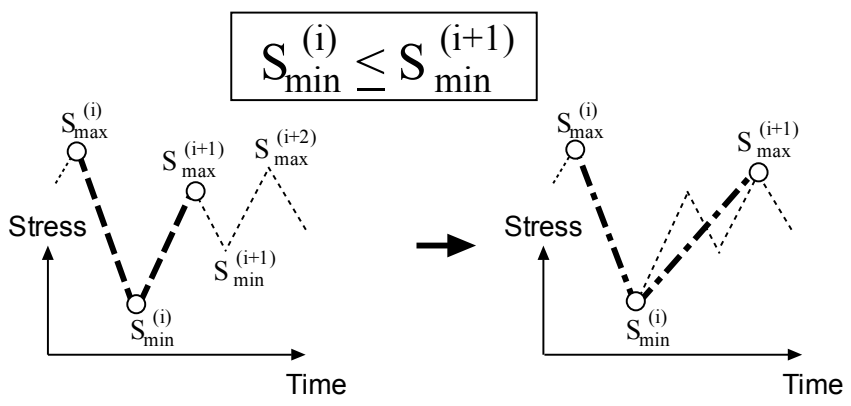

(c) Effective stress sequence extracting method Pattern 2

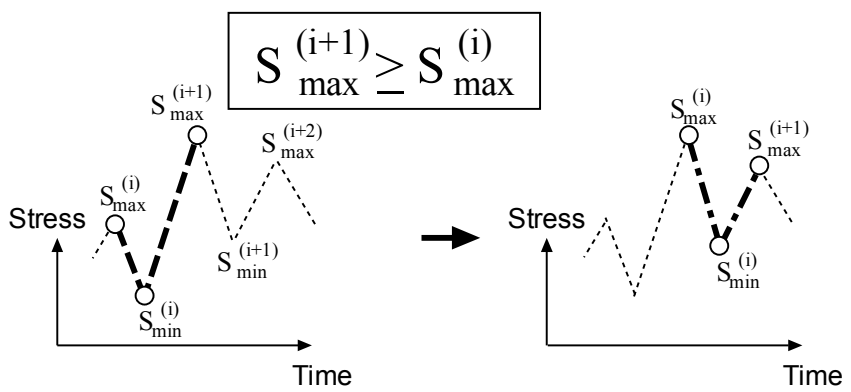

(d) Effective stress sequence extracting method Pattern 3

Fig. 6 Extracting procedure for the effective stress sequence during random loading. 
3.3 Numerical simulation of fatigue crack propagation based on the RPG stress criterion

Numerical simulations of fatigue crack propagation were performed based on the Paris' fatigue crack propagation law using the RPG stress criterion shown in Eq. (5).

$$
d a / d N=C\left(\Delta K_{R P G}\right)^{m}
$$

where $a$ is the crack length, $N$ is the number of loading cycles, $\Delta K_{R P G}$ is the effective stress intensity factor range based on the RPG stress criterion, and $C$ and $m$ are material constants. The material constants $C$ and $m$ in Eq. (5) were identified by the relation between $\Delta K_{R P G}$ and $d a / d N$ measured under a constant stress amplitude without superimposed stress conditions (tests L4t, Pa4t_H, Pa4t_M, and Pa4t_L) as shown in Fig. 7. To determine $\Delta K_{R P G}$ we followed the procedures presented in reference [13]. The estimated curve in Fig. 7 was obtained from experiment data by the least square method.

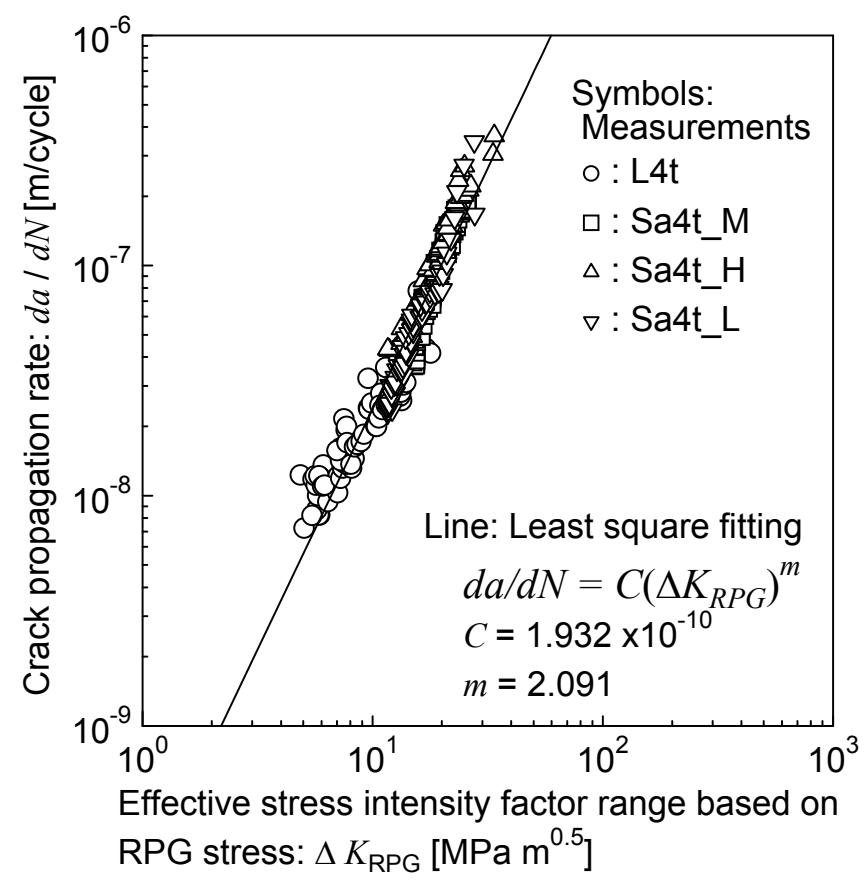

Fig. 7 Relations between $d a / d N$ and $\Delta K_{\mathrm{RPG}}$ 
We performed numerical simulations of fatigue crack propagation under all the applied stress histories (Table 3) except for test L4t, because the object of test L4t was to obtain the material constants $C$ and $m$ for the RPG stress criterion of the fatigue crack propagation law.

The value of the threshold plastic work $\xi_{\text {limit }}$ defined by Eq. (4) was set to $0.3 \mathrm{~N} / \mathrm{mm}$ by trial and error to obtain good estimates from the numerical simulations. The physical meaning of $\xi_{\text {limit }}$ is discussed in the following section.

In Figures 8 (a)-(h) the simulated fatigue crack propagation histories are compared with the measured ones. The symbols and curves in these figures refer to the measured and numerical simulation results, respectively. The horizontal axis in these figures represents the number of low-frequency components of the applied loading cycles. Figures 8 (a)-(d) and (g) were drawn by setting the origin when the crack tip reaches $7 \mathrm{~mm}$ from the center of the specimen, i.e. the fatigue crack length reaches about $1 \mathrm{~mm}$. Figures 8 (e), (f), and (h) were drawn by setting the origin when the applied number of cycles of the low-frequency component reaches 20,000 . The origins were set in this way to evaluate the stable fatigue crack propagation stage. 


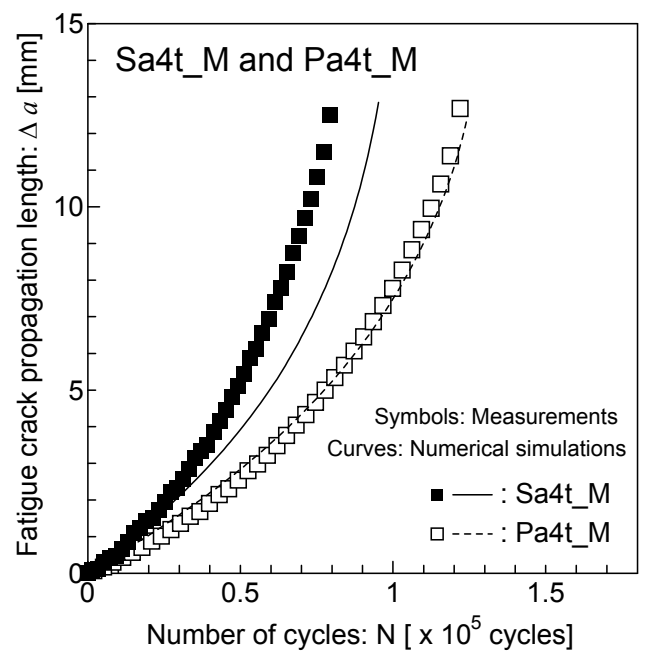

(b) Sa4t_M and Pa4t_M

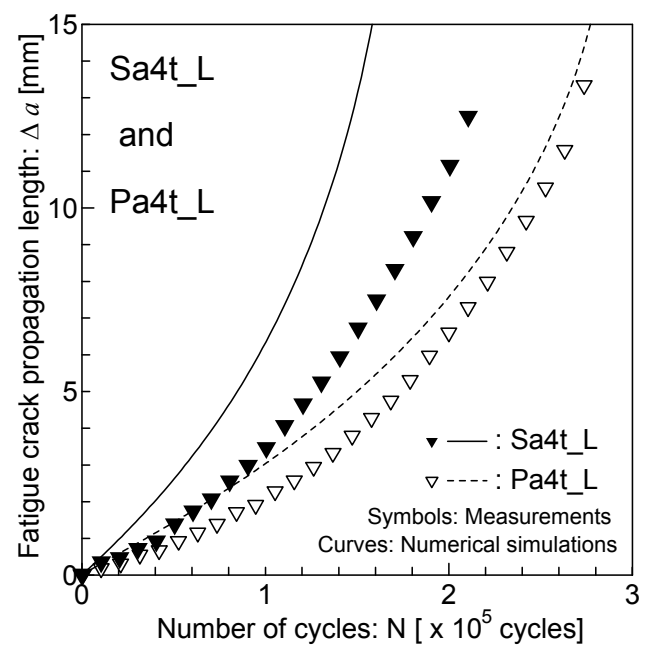

(d) Sa4t_L and Pa4t_L

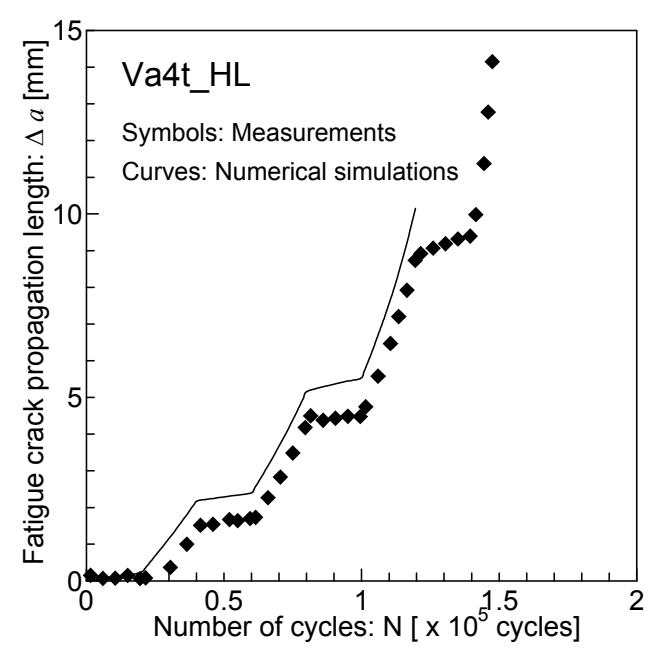

(e) Va4t_HL

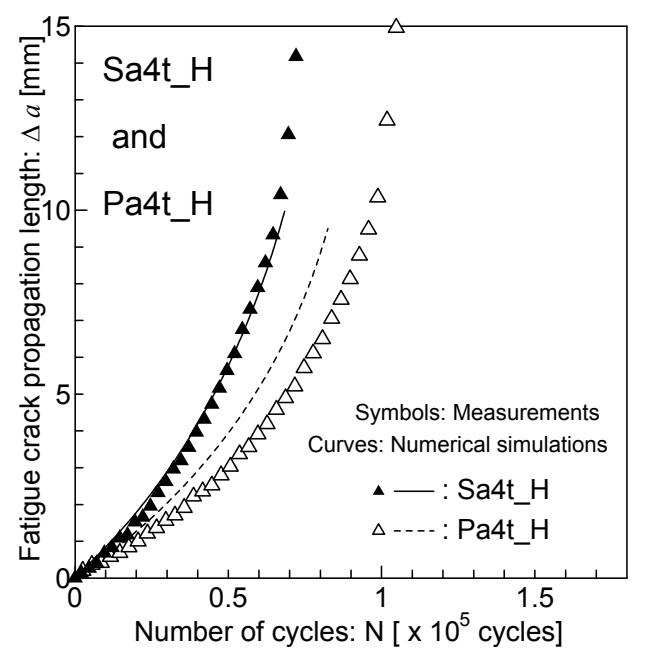

(a) Sa4t_H and Pa4t_H

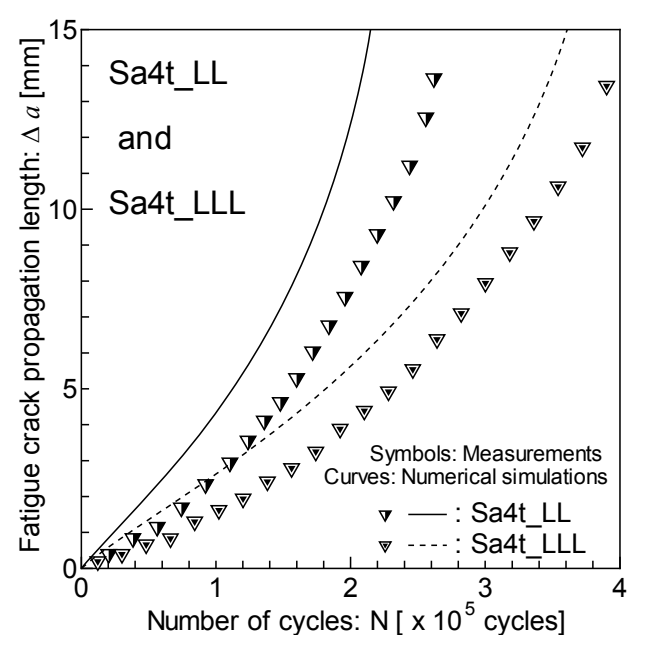

(d) Sa4t_LL and Sa4t_LLL

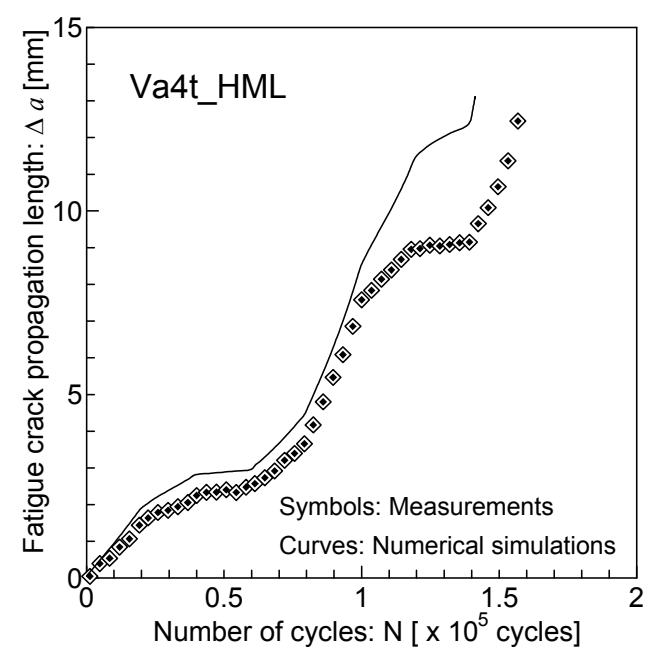

(f) Va4t_HML 


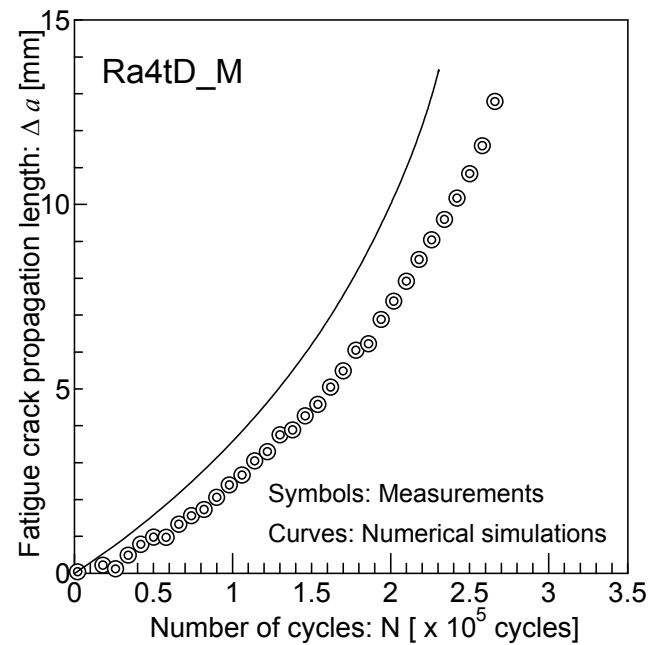

(g) Ra4tD_M

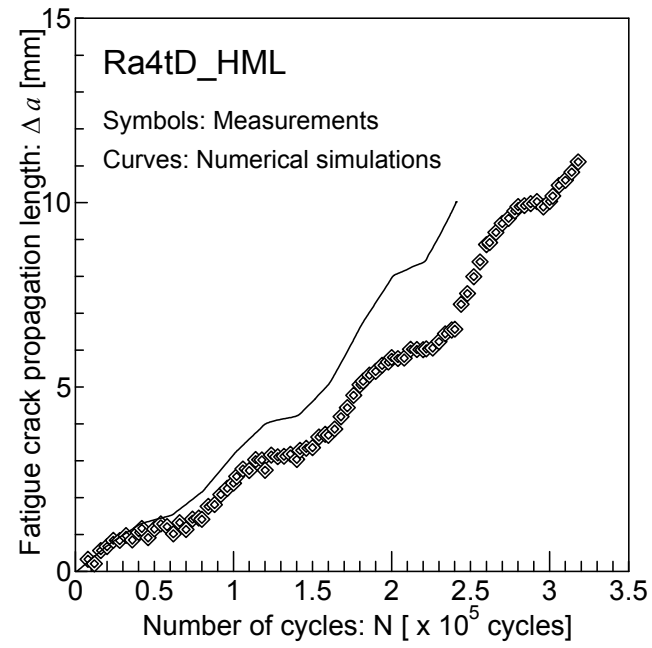

(h) Ra4tD_HML

Fig. 8 Comparison of measured crack growth curves and estimated ones under variable stress sequences.

The numerical simulation results were in good agreement with the measured fatigue crack propagation curves, with the simulated crack growth curves slightly more conservative than the measured ones.

Figure 9 shows examples of the extracted effective stress history for each test when the fatigue crack length reaches about $5 \mathrm{~mm}$. Any high-frequency, small-amplitude component that could not generate $\xi$ (as defined by Eq. (4)) exceeding the threshold $\xi_{\text {limit }}$ during one cycle, was ignored as an effective loading for the fatigue crack growth.

Moreover, the higher frequency components were extracted as the effective stress history for fatigue crack growth in case the value of mean stress was high, see Fig. 9 (a)-(e).

Although the applied stress histories of the lower mean stress stage of Fig. 9 (f) (test Va4t_HL) and Fig. 9 (g) (Test Va4t_HML) were the same as that of Fig. 9 (c) (Test Sa4t_L), the extracted effective stress histories in each condition were different. This may be caused by the difference in the plastic zone and crack wake evolutions due to the effect of the applied stress sequence on the fatigue crack growth. 


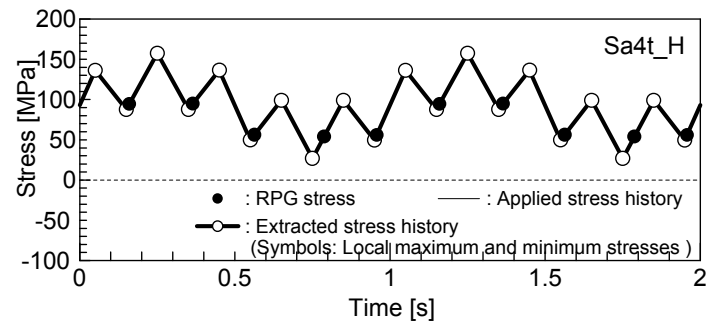

(a) Sa4t_H

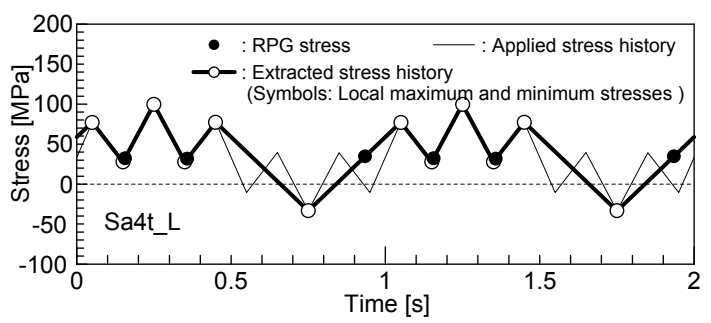

(c) Sa4t_L

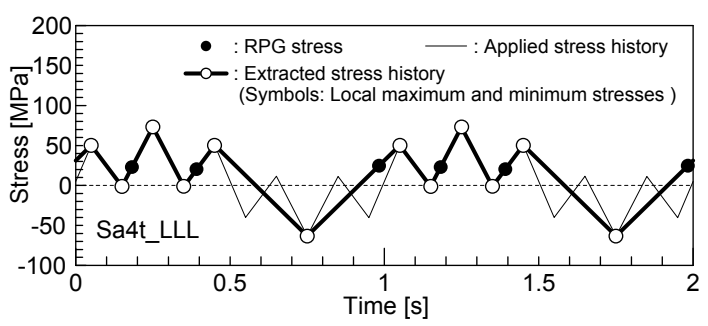

(e) Sa4t_LLL

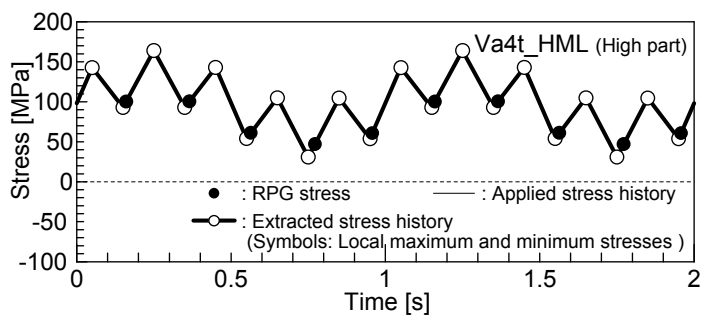

(g-i) Va4t_HML (High part)

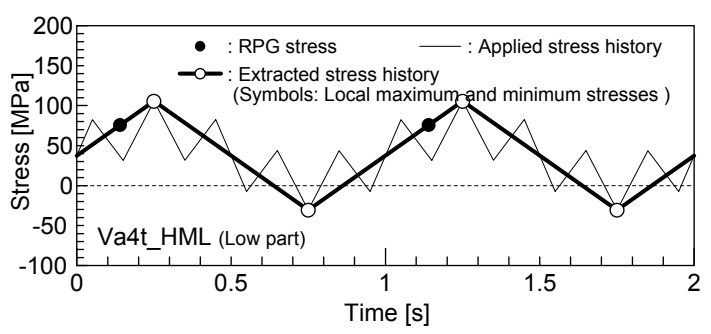

(g-iii) Va4t_HML (Low part)

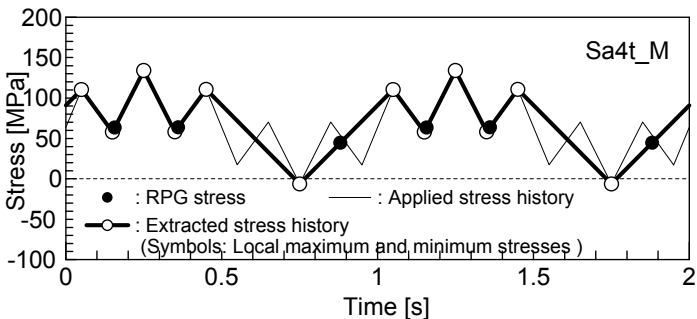

(b) Sa4t_M

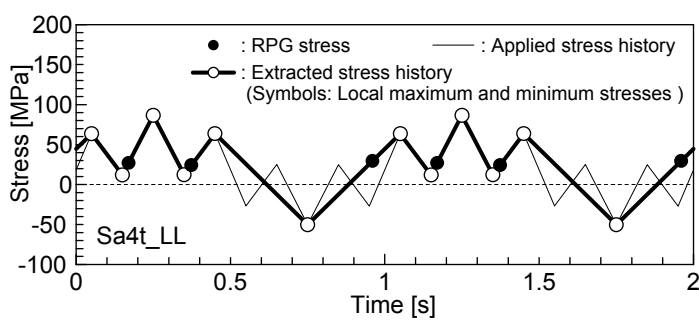

(d) Sa4t_LL

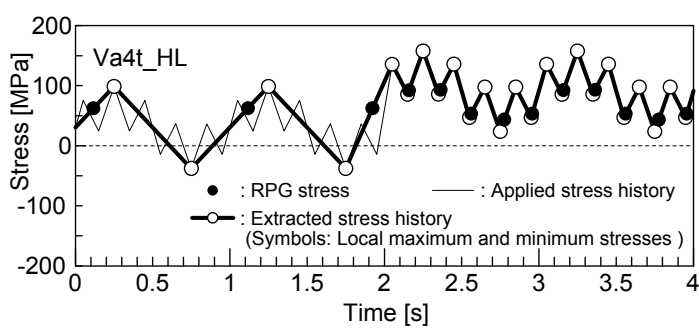

(f) Va4t_HL

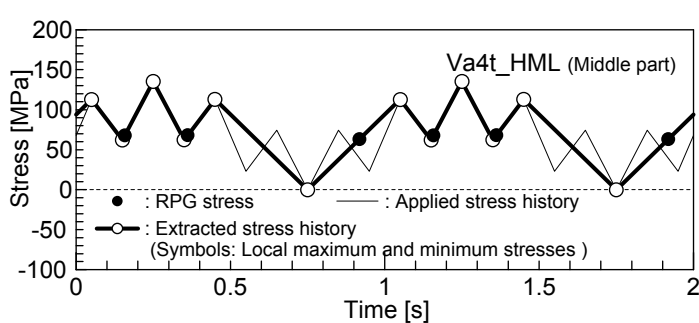

(g-ii) Va4t_HML (Middle part)

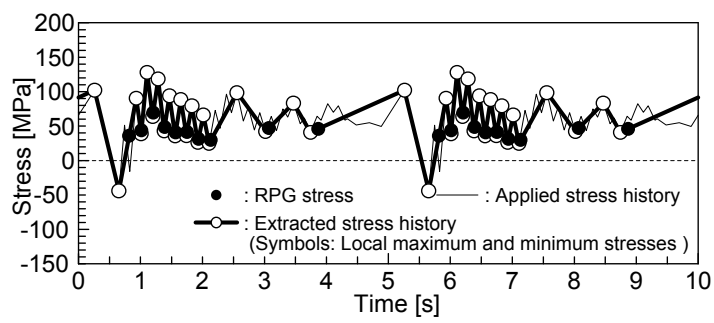

(h) Ra4tD_M 


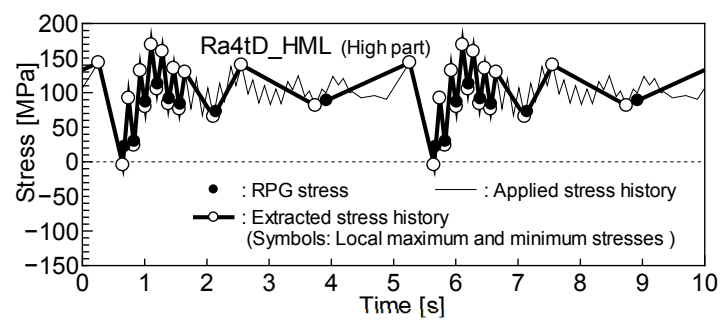

(i-i) Ra4tD_HML (High part)

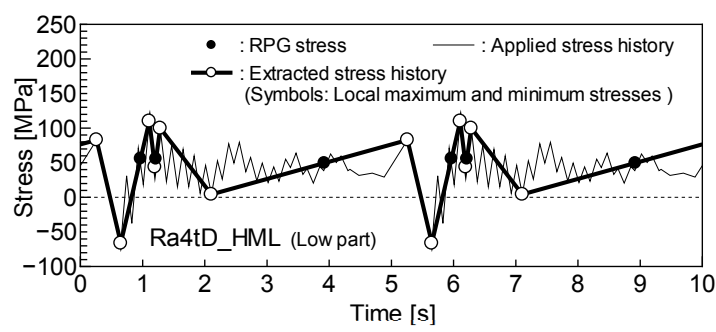

(i-iii) Ra4tD_HML (Low part)

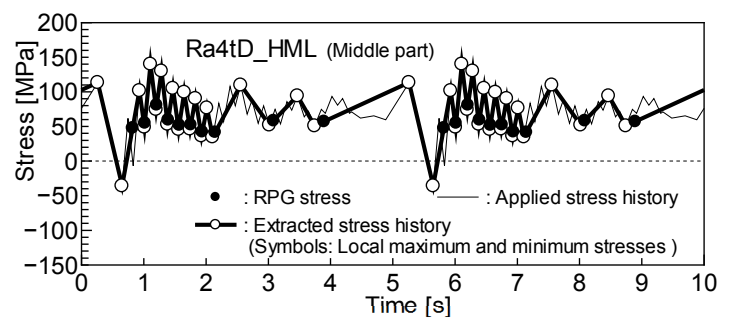

(i-ii) Ra4tD_HML (Middle part)

Fig. 9 Examples of the extracted effective stress sequences under variable loadings.

3.4 The physical meaning of the threshold for the extraction of the effective stress history

As defined by Eq. (4), the extraction criterion of effective stress history for fatigue crack propagation ( $\xi)$ represents the alternating plastic work consumed near a crack tip during one stress cycle. Therefore, the value of the alternating plastic work per unit volume during one stress cycle could be defined by dividing $\xi$ into the product of the alternating plastic zone length $(\tilde{\omega})$ and the plate thickness $(t)$. Figure 10 shows the values of $\xi / \tilde{\omega} t$ for the extracted effective stress histories according to the crack growth for all the experimental conditions in this study.

The amount of plastic hysteresis $\left(W_{p 0}\right)$ at a plastic strain value of $0.2 \%$ is highlighted to refer to the threshold of the plastic hysteresis at the initial yielding stage. The stress versus strain relation of the material was assumed to be an elastic - perfect plastic medium. The value of $W_{p 0}$ was equal to $1.83 \mathrm{MPa}$ and drawn in Fig. 10 by a dash-dotted curve. All the values of $\xi / \tilde{\omega} t$ were higher than those of $W_{p 0}$. Considering that a plastic strain of $0.2 \%$ defines the proof stress of the material, and the strain hardening effect of the material was ignored in these simulations, the applied threshold value in the simulations indicates that the alternating 
plastic hysteresis consumed in the vicinity of the crack tip must be generated to supply the driving force for the fatigue crack propagation.

Additionally, the value of $\xi$ was higher than the lower limit value ( $\left.\xi_{\text {limit }}=0.3\right)$ at a very low fatigue crack propagation rate $\left(1.0 \times 10^{-11} \mathrm{~m} /\right.$ cycle $)$ during the stress intensity factor range decreasing test [14]. This result implies that the value of $\xi$ is independent of the threshold of the stress intensity factor range.

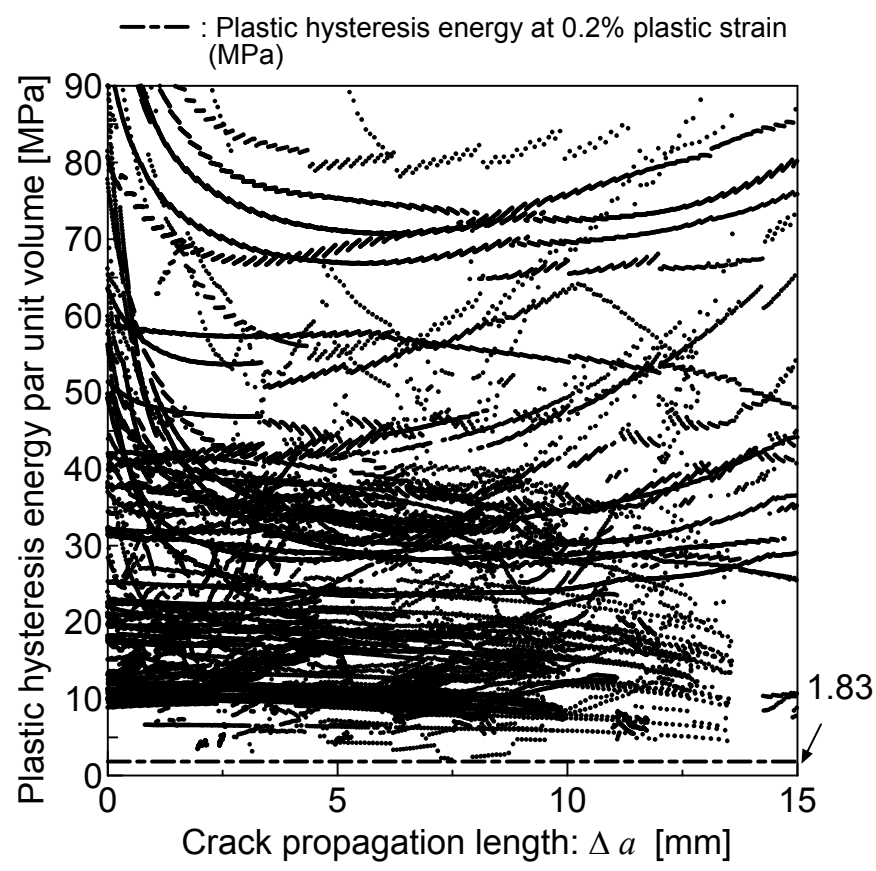

Fig. 10 Evolution of the plastic work consumed in the vicinity of the crack tip

4. Validation of fatigue life evaluation by applying the S-N curves approach

Here, we investigate the applicability of the conventional fatigue life evaluation procedure based on the S-N curves approach for the superimposed frequency components problem.

The S-N curve was derived from the test results under constant amplitude stresses as shown in Table 4 and Eq. (6). Reference stress value at two million cycles which corresponds to IIW FAT Class is 56.8 MPa.

The definition of the fatigue lives in this chapter refers to a fatigue crack length of about $5 \mathrm{~mm}$. The 
exponent $m$ of the S-N curve was set to the same value of the UK-HSE design D curve [15] and a least squares fitting was performed to identify the constant $K$ in Eq. (6). Additionally, each stress range was converted to a mean stress of 0 by the modified Goodman's relation. Haibach's modification [16] was applied in the cycle range of more than $10^{7}$ of the S-N curve.

$$
S^{m} N=K,
$$

where $S$ is the stress range and $N$ is the number of cycles to failure.

Table 4 Estimated S-N curve.

\begin{tabular}{cccc}
\hline \multicolumn{2}{c}{$N \leq 1.0 \times 10^{7}$} & \multicolumn{2}{c}{$N>1.0 \times 10^{7}$} \\
\hline$m$ & $K$ & $m$ & $K$ \\
\hline 3.000 & $3.661 \times 10^{11}$ & 5.000 & $4.037 \times 10^{14}$ \\
\hline
\end{tabular}

The values of the linear cumulative fatigue damage parameter $D$ were calculated by applying the S-N curves mentioned above and the rain flow counting results for each raw applied stress histories. The values of the linear cumulative fatigue damage parameter $D_{\text {eff }}$ were calculated by applying the S-N curves mentioned above and the effective stress histories obtained by our numerical simulations mentioned in the previous section and Fig. 9.

The results are shown in Table 5. The values of $D$ were obtained under raw applied stress histories and the $D_{\text {eff }}$ values were obtained under the extracted effective stress histories by the numerical simulation of fatigue crack propagation. The parameter $\sigma_{m}$ represents the mean stress of each test condition. 
Table 5 Results of fatigue life evaluation.

\begin{tabular}{|c|c|c|c|}
\hline Test ID & $D$ & $D_{e f f}$ & $\sigma_{m}[\mathrm{MPa}]$ \\
\hline $\mathrm{L} 4 \mathrm{t}$ & 0.675 & - & 65 \\
\hline Pa4t_H & 0.900 & - & 95 \\
\hline Pa4t_M & 0.985 & - & 65 \\
\hline Pa4t_L & 1.479 & - & 35 \\
\hline Sa4t_H & 0.690 & 0.690 & 95 \\
\hline $\mathrm{Sa} 4 \mathrm{t} \_\mathrm{M}$ & 0.711 & 0.659 & 65 \\
\hline Sa4t_L & 1.251 & 1.154 & 35 \\
\hline Sa4t_LL & 1.504 & 1.385 & 20 \\
\hline Sa4t_LLL & 2.025 & 1.867 & 5 \\
\hline Va4t_HL & 1.031 & 0.956 & 95,35 \\
\hline Va4t_HML & 1.173 & 1.091 & $95,65,35$ \\
\hline Ra4tD_M & 0.791 & 0.750 & 65 \\
\hline Ra4tD HML & 1.094 & 1.009 & $95,65,35$ \\
\hline
\end{tabular}

The constant mean stress conditions (tests Pa4t_H, Pa4t_M, and Pa4t_L) in Table 5 confirmed that high fatigue damage parameter values occurred when the mean stress was low.

A similar tendency was confirmed under regular superimposed stress conditions with different mean stresses (tests Sa4t_H, Sa4t_M, Sa4t_L, Sa4t_LL, and Sa4t_LLL). The ratio of the high-frequency loading component, which did not contribute to the fatigue crack propagation, increased according to the decreasing mean stress. In contrast, the scatter of $D_{\text {eff }}$ under different mean stress conditions was smaller than that of $D$.

These results indicate that the contribution of the high-frequency component of the superimposed stress 
condition on the fatigue damage parameter $D$ was less than the low-frequency component. This tendency was similar to those found in other studies [1] [5].

Conversely, a relatively good agreement was obtained under variable mean stress conditions (Table 5). This suggests that the mean stress effect on the fatigue damage parameter was canceled by the high and low mean stress conditions.

\section{Conclusions}

The validity of the extraction algorithm for the effective stress histories for fatigue crack propagation under superimposed stress histories under different and variable mean stress conditions was investigated. The critical value of the alternating plastic work was applied as the control parameter for extracting the effective stress sequences. Fatigue crack propagation tests under superimposed stress histories with various mean stress conditions were performed and the results were compared with fatigue crack growth curves obtained by numerical simulation. The comparison results demonstrated the validity of the extraction algorithm and showed that the effective stress sequences that contribute to fatigue crack growth were affected by the high-frequency stress amplitude as well as the mean stress.

Furthermore, a practical fatigue-life evaluation method based on the S-N curves approach with rain flow counting was investigated to consider the mean stress effect on fatigue crack growth under superimposed stress histories. The results confirmed that high damage parameter values were obtained at low mean stress conditions. 
Acknowledgments

This research was funded by JSPS Grant-in-Aid for Scientific Research (A) (26249136) and JSPS

Fellows (26004132) from the Japan Society for the Promotion of Science.

Mr. Koji Murakami, Senior Technician of Kyushu University, contributed to the experimental work of this study.

References

[1] Fricke W, Paetzold H. 2013. Experimental Investigations on Fatigue Damage of Ship Structures Caused by Whipping Stresses. Proc. of PRADS, 465-470.

[2] Toyoda K, Matsumoto T, Yamamoto N, Terai K. 2012. Simplified Fatigue Assessment Considering the Occurrence Probability of Hydro-Elastic Response in Actual Sea State Conditions. Proc. of Hydroelasticity in Marine Technology, 367-376.

[3] ASTM E1049-85. 2011. Standard Practices for Cycle Counting in Fatigue Analysis.

[4] Fricke W, Paetzold H. 2012. Experimental Investigation of the Effect of Whipping Stresses on the Fatigue Life of Ships. Proc. of Int. Marine Design Conf., 3, 3-10.

[5] Osawa N, Nakamura T, Yamamoto N, Sawamura J. 2014. Experimental Study on High Frequency Effect on Fatigue Strength of Welded Joints by Using Plate-Bending-Vibration Type Fatigue Testing Machine. Proc. of OMAE2014, OMAE2014-23856.

[6] Schütz W. A. 1996. History of Fatigue, Engineering Fracture Mechanics, 54(2), 263-300.

[7] Toyosada M, Gotoh K, Niwa T. 2003. Fatigue crack propagation for a through thickness crack tip. Int. J. of Fatigue, 26(9), 983-992.

[8] Gotoh K, Matsuda K, Kitamura O. 2012. Numerical Simulation of Fatigue Crack Propagation under Superposed Loading Histories with Two Different Frequencies. Proc. of 6th Int. Conf. on Hydroelasticity in Marine Technology, 287-297. 
[9] Matsuda K, Gotoh K. 2013. Numerical Simulation of Fatigue Crack Propagation under Simulated Whipping Loading Arising in Hull Structures. Proc. of OMAE 2013, OAME2013-10985.

[10] Japanese Industrial Standard. 2008. JIS G 3106 Rolled steels for welded structure, Japan.

[11] Newman, Jr. J.C. (1981) A Crack-Closure Model for Predicting Fatigue Crack Growth under Aircraft Spectrum Loading, NASA Tech. Memo., 81941.

[12] Newman Jr. J.C. (1992) FASTRAN-II: A FATIGUE CRACK GROWTH STRUCTURAL ANALYSIS PROGRAM, NASA Tech. Memo., 104156.

[13] Toyosada M, Niwa T. 1994. The significance of RPG load for fatigue crack propagation and the development of a compliance measuring system. Int. J. of Fracture; 67, 217-30.

[14] Gotoh K, Matsuda K. 2013. Numerical Simulation of Fatigue Crack Propagation under Variable Amplitude Loading Containing Two Different Frequency Components. J. JASNAOE, 17, 75-81.

[15] Health and Safety Executive (UK-HSE). 2012. Status of technical guidance and information on design, construction and operation of offshore installation.

[16] Haibach E. 1971. The allowable stresses under variable amplitude loading of welded Joints. Conference on fatigue of welded structures; The Welding Institute, 2, 328-339. 